\title{
REAPPRAISAL OF THE ACTIVITY OF CLAYS. ACTIVITY CHART
}

\author{
ENNIO POLIDORI ${ }^{\text {i) }}$
}

\begin{abstract}
The proposed activity chart, which aims to classify soils $(<425 \mu \mathrm{m})$ using the Atterberg limits, differs from the plasticity chart recently proposed by the author because the inorganic soils with platey clay minerals are classified (in addition to clay percentage) on the basis of their activity rather than on the degree of plasticity as a function of the liquid limit value, currently used by the standards. This is because soils that have the same liquid limit value may have very different characteristics because of both the amount and type of clay minerals contained in the soils. On the activity chart, the silt and the clay zones are subdivided (by two straight lines) in three new groups (low activity, medium activity and high activity) making it possible to classify inorganic soils with platey clay minerals (or their fraction) $<425 \mu \mathrm{m}$ on the basis of the amount and type of clay minerals they contain. The activity chart adapted to predict residual shear behaviour of cohesive soils is also shown. Finally, the distinction between coarse-grained soils and fine-grained soils based on their percentage of clay $(<2 \mu \mathrm{m})$, might be useful in characterizing and predicting soils' engineering behaviour.
\end{abstract}

Key words: Atterberg limits, clay, laboratory tests, plasticity, residual strength, soil classification (IGC: D1/D3/D6)

\section{INTRODUCTION}

Soil properties and their engineering behaviour, apart from stress history, are markedly influenced by the physicochemical characteristics of the constituent clay and non-clay minerals and their relative proportions. Generally, two fractions with different behaviours can be distinguished in clayey soils. The "active, binder" fraction composed of clay mineral particles (which in routine assessments of soil properties, is conventionally assumed to be constituted by particles $<2 \mu \mathrm{m}$, termed clay fraction, $C F$ ) and the "inert" fraction composed of non-clay mineral (round) particles (conventionally $>2 \mu \mathrm{m}$ ).

It is known that the very different behaviour of clay and non-clay minerals can be attributed to the plasticity of the clay minerals. In fact, non-clay minerals (as quartz, feldspar, etc.) do not develop plastic mixtures with water, even when ground to sizes less than $2 \mu \mathrm{m}$ (Casagrande, 1932). Hence, to classify soils with a high percentage of fine materials the content and type of clay minerals present also take on great importance. The Atterberg limits (Casagrande, 1932, 1958) reflect the composite effects of the soil constituents and their interactions with pore fluid. The liquid limit, $W_{\mathrm{L}}$, the plastic limit, $W_{\mathrm{p}}$, and their numerical difference, the plasticity index, $I_{\mathrm{p}}$, constitute a widely used method of soil $<425 \mu \mathrm{m}$ characterization and classification (Casagrande, 1948; Polidori, 2003) and predicting cohesive soils' engineering behaviour.
A first distinction among soils based on their behavioural characteristics can be drawn between organic soils and inorganic soils. Inorganic soils containing platey clay minerals, namely common inorganic soils (with the same clay percentage), show similar behaviour that is very different from those containing non-platey clay minerals (characterized by high plastic limit, low plasticity index, etc.; Mitchell, 1993). Hence, the following considerations regarding the intrinsic properties are valid for inorganic soils with only platey shape clay minerals (such as kaolinite, illite, montmorillonite). Finally, the distinction between fine-grained soils and coarse-grained soils currently adopted by standards for soil classification is investigated.

\section{THE PLASTICITY CHART AND INDEX PROPERTIES}

\section{Soil Classification using the Plasticity Chart}

In a previous paper the author proposed a new plasticity chart (Polidori, 2003) to classify soils (or their fraction) $<425 \mu \mathrm{m}$ using the well-known Atterberg limits. In Fig. 1, all the $I_{\mathrm{p}}-W_{\mathrm{L}}$ values of the inorganic soils containing platey clay minerals and $C F<100 \%$ should lie above the $\mathrm{C}$-line and the distance of the points from the $\mathrm{C}$-line should be inversely proportional to the clay percentage of the respective soils. The $0.5 \mathrm{C}$-line allows us to distinguish the points that fall below the line, clays (soils with $C F \geq 50 \%$ ), from the points lying above the line in the silt

i) Department GEOTECA (Geological Sciences), University of Urbino 'Carlo Bo', Scientific Campus, Italy (ennio.polidori@uniurb.it). The manuscript for this paper was received for review on July 16, 2008; approved on March 26, 2009.

Written discussions on this paper should be submitted before January 1, 2010 to the Japanese Geotechnical Society, 4-38-2, Sengoku, Bunkyo$\mathrm{ku}$, Tokyo 112-0011, Japan. Upon request the closing date may be extended one month. 


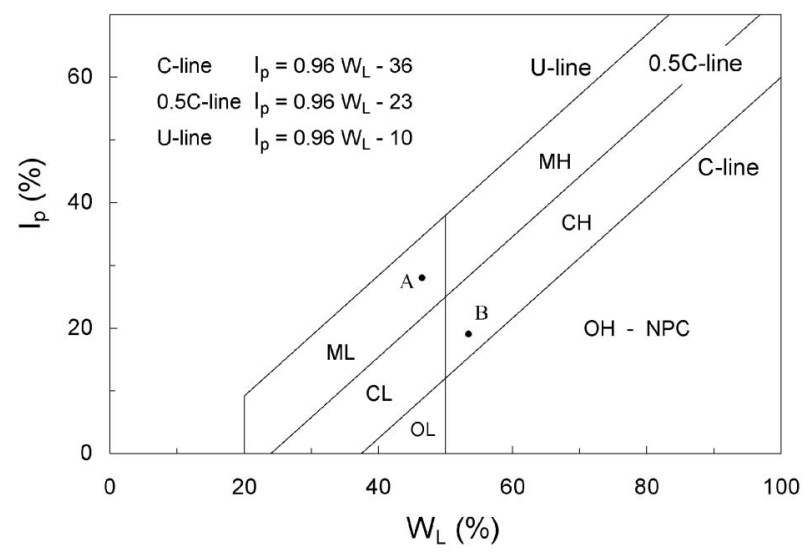

Fig. 1. Plasticity chart (after Polidori, 2003). C-line and 0.5C-line correspond to $100 \% \mathrm{CF}$ and $50 \% \mathrm{CF}(<2 \mu \mathrm{m})$, respectively. $\mathrm{CL}, \mathbf{C H}$ $=$ clay zone $(C F \geq 50 \%)$. ML, MH $=$ silt zone $(2-425 \mu \mathrm{m}>50 \%)$. $\mathrm{OL}, \mathrm{OH}=$ organic soils. $\mathrm{NPC}=$ soils with non - platey clay minerals. Low plasticity (L) and high plasticity (H) based on ASTM standard (D 2487). A and $B=$ example of two soil types

zone.

In turn, the silt zone (M) and clay zone (C) can be subdivided into groups with low $(\mathrm{L})$ or high $(\mathrm{H})$ plasticity, according to the ASTM standard (D 2487) when the liquid limit value is less than or greater than $50 \%$, respectively.

In the same figure, it can be observed that an inorganic soil with $W_{\mathrm{L}}<50 \%$ and a low clay size content, such as soil A, may lie in the low plasticity silt zone (ML), whereas an inorganic soil with $W_{\mathrm{L}}>50 \%$ and a high clay fraction, such as soil B, may lie in the high plasticity clay zone $(\mathrm{CH})$, although the plasticity index (and activity) of clay B is lower than that of silt A.

In a soil, when the clay fraction decreases, due to dilution (adding particles $2-425 \mu \mathrm{m}$ ), its $W_{\mathrm{L}}$ (and $I_{\mathrm{p}}$ ) also decreases to values less than $50 \%$ because the effect of the clay fraction is incorporated into the Atterberg limit values modified by dilution. Hence, the distinction between the high and low plasticity of soils (used by the standards, as ASTM and BS) as a function of the liquid limit value is indirectly based on the percentage of clay. In other words, when classification is based on the liquid limit value, the characteristics (expandability, activity) of the clay minerals contained in the soil are ignored, and the distinction based on the clay fraction occurs through the silt and clay zones, where the $I_{\mathrm{p}}-W_{\mathrm{L}}$ data of the common inorganic soils should lie.

\section{Some Considerations on the Index Properties}

The type of platey clay mineral (also a function of the type of cation absorbed) may cause very strong variations in Atterberg limit values, even though the clay percentage remains the same. This can be inferred from Polidori's plasticity chart (Fig. 1). In fact, for inorganic soils (with platey clay minerals), the location of $\left(W_{\mathrm{L}}-I_{\mathrm{p}}\right)$ data that lie on the (lines of constant $C F$ ) $0.5 \mathrm{C}$-line and C-line depends on the characteristics of the clay minerals they contain. The lowest and highest values belong to clay miner- als kaolinite and montmorillonite, respectively. Moreover, even soils that have the same $W_{\mathrm{L}}$ (or $I_{\mathrm{p}}$ ) value may have very different characteristics because of the amount and type of their clay minerals. For example, a soil with higher silt and/or sand contents $(<425 \mu \mathrm{m})$, with the same liquid limit, shows an even higher plasticity index because it must contain clay minerals that are increasingly expandable as the clay fraction decreases. Therefore, it can be concluded that neither the Atterberg limits nor the clay percentage alone suffices to characterize, classify and predict fine soil behaviour. To separate the effects of the amount and type of clay minerals incorporated into the Atterberg limit values of a soil, the ratio of the plasticity index to the clay fraction, termed the activity $\left(A=I_{\mathrm{p}} / C F\right)$, (Skempton, 1953) is very useful.

In Polidori (2007) the interdependence among the parameters ( $W_{\mathrm{L}}, W_{\mathrm{p}}, I_{\mathrm{p}}, A$ and $C F$ of the tested soil) was observed for inorganic soils containing platey clay minerals and a clay percentage that was not too low (until the non-clay particles are still not in contact with one another; for details, see the cited paper). The quantitative relationship that includes these parameters, with respect to the plasticity index (in agreement to three equations reported in Fig. 1) is as follows:

$$
I_{\mathrm{p}}=0.96 W_{\mathrm{L}}-(0.26 C F+10)
$$

where it can be observed that the plasticity index of a soil is related to the liquid limit and clay fraction of the soil used for the Atterberg limits test.

Therefore, for inorganic soils that contain platey clay minerals (according to activity defined by Skempton, 1953), the activity will be:

$$
A=\left[0.96 W_{\mathrm{L}}-(0.26 C F+10)\right] / C F
$$

Both values, $W_{\mathrm{L}}$ and $C F$ characterize the same soil fraction. Currently, to calculate the activity, Atterberg limits (of a soil $<425 \mu \mathrm{m}$ ) are related to the clay percentage of the entire soil. The possible presence of particles $>425$ $\mu \mathrm{m}$ in a soil would produce an overestimate of the activity value.

The activity depends on many factors (type of clay mineral, type of absorbed cation, $\mathrm{pH}$, degree of crystallinity, etc.) and their combination provides a wide range of activity values, where the minimum and maximum values belong to the pure clay minerals kaolinite and montmorillonite (in monovalent ionic form), respectively. The higher the activity of a soil, the more important the influence of the clay fraction on the intrinsic properties and the more susceptible their values are to changes in such factors as the type of exchangeable cations and pore fluid composition.

Because the activity of a soil is equal to the ratio between plasticity index value and its percentage of clay, it is possible to obtain the values of the plasticity index as a function of the clay fraction for a given activity value:

$$
I_{\mathrm{p}}=A C F
$$


Table 1. Plasticity index, $I_{\mathrm{p}}$ and liquid limit, $W_{\mathrm{L}}$ (calculated with Eqs. (3) and (4) respectively) as a function of clay fraction, $C F$ for given activity, $A$ values

\begin{tabular}{|c|c|c|c|c|c|c|c|c|c|}
\hline$C F$ & $q$ & $\begin{array}{c}I_{\mathrm{p}} \\
\text { for }\end{array}$ & $\begin{aligned} & W_{\mathrm{L}} \\
= & 0.50\end{aligned}$ & $\begin{array}{r}I_{\mathrm{p}} \\
\text { for }\end{array}$ & $\begin{aligned} & W_{\mathrm{L}} \\
= & 0.75\end{aligned}$ & $\begin{array}{r}I_{\mathrm{p}} \\
\text { for }\end{array}$ & 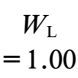 & $\begin{array}{c}I_{\mathrm{p}} \\
\text { for }\end{array}$ & $\begin{aligned} & W_{\mathrm{L}} \\
= & 1.25\end{aligned}$ \\
\hline 100 & 36 & 50 & 89.6 & 75 & 115.6 & 100 & 141.7 & 125 & 167.7 \\
\hline 90 & 33.4 & 45 & 81.7 & 67.5 & 105.1 & 90 & 128.5 & 112.5 & 152.0 \\
\hline 80 & 30.8 & 40 & 73.7 & 60 & 94.6 & 80 & 115.4 & 100 & 136.2 \\
\hline 70 & 28.2 & 35 & 65.8 & 52.5 & 84.1 & 70 & 102.3 & 87.5 & 120.5 \\
\hline 60 & 25.6 & 30 & 57.9 & 45 & 73.5 & 60 & 89.2 & 75 & 104.8 \\
\hline 50 & 23 & 25 & 50.0 & 37.5 & 63.0 & 50 & 76.0 & 62.5 & 89.1 \\
\hline 40 & 20.4 & 20 & 42.1 & 30 & 52.5 & 40 & 62.9 & 50 & 73.3 \\
\hline 30 & 17.8 & 15 & 34.2 & 22.5 & 42.0 & 30 & 49.8 & 37.5 & 57.6 \\
\hline 20 & 15.2 & 10 & 26.2 & 15 & 31.5 & 20 & 36.7 & 25 & 41.9 \\
\hline 10 & 12.6 & 5 & 18.3 & 7.5 & 20.9 & 10 & 23.5 & 12.5 & 26.1 \\
\hline 0 & 10 & 0 & 10.4 & 0 & 10.4 & 0 & 10.4 & 0 & 10.4 \\
\hline
\end{tabular}

$C F=(\%<2 \mu \mathrm{m}) ; q=(0.26 C F+10) ; I_{\mathrm{p}}$ and $W_{\mathrm{L}}$ are in $\%$

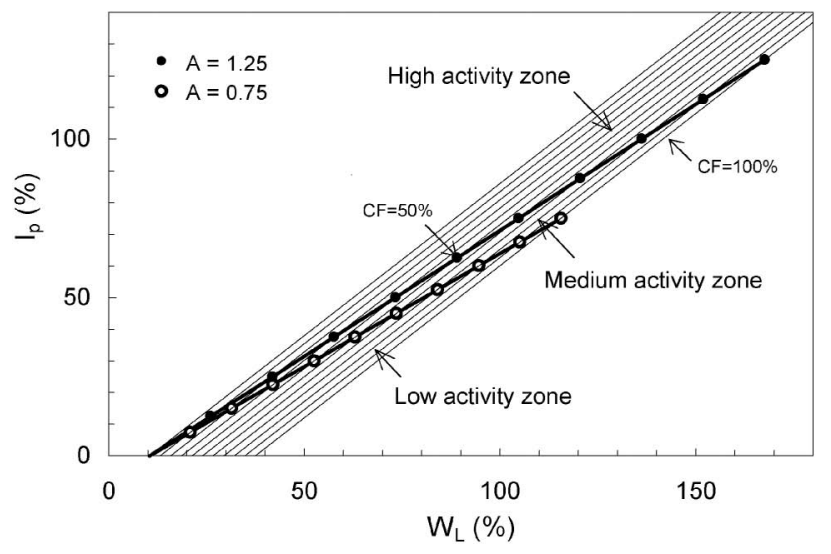

Fig. 2. Relationship among plasticity index, $I_{\mathrm{p}}$, liquid limit, $W_{\mathrm{L}}$ and clay fraction, $C F(<2 \mu \mathrm{m})$, for activity, $A$ values 0.75 and 1.25 shown in Table 1. The bold lines define three zones with different ranges of activity values. The thin lines connect $\left(I_{\mathrm{p}}-W_{\mathrm{L}}\right)$ data with the same $C F$ ranging $10 \%$

The liquid limit from Eq. (1) is:

$$
W_{\mathrm{L}}=\left(I_{\mathrm{p}}+q\right) / 0.96
$$

where $q=(0.26 C F+10)$. For inorganic soils with platey clay minerals Eqs. (3) and (4) make it possible to obtain the plasticity index and then the liquid limit values when the clay percentage and activity values are known. Table 1 shows liquid limit values and their corresponding plasticity index values as a function of clay fraction for some activity values. Using the activity values 0.75 and 1.25 , Skempton (1953) classified clays into three groups: inactive clays $(A<0.75)$, normal clays ( $A 0.75$ to 1.25 ) and active clays $(A>1.25)$.

In Fig. 2 the thin lines connect the $\left(I_{\mathrm{p}}-W_{\mathrm{L}}\right)$ values with the same $C F$, ranging $10 \%$ and clearly those corresponding to $C F=50 \%$ and $C F=100 \%$ have the same equations of the $0.5 \mathrm{C}$-line and $\mathrm{C}$-line, respectively, according to Eq. (1). The same figure, on the basis of the values of $I_{\mathrm{p}}$ and $W_{\mathrm{L}}$ (for Skempton's activity values 0.75 and 1.25) reported in Table 1, shows two bold straight lines making it possible to distinguish three zones, located
Table 2. Activities of clay minerals, from Mitchell (1993)

\begin{tabular}{lc}
\hline Mineral & Activity \\
\hline Montmorillonite & $1-7$ \\
Illite & $0.5-1$ \\
Kaolinite & $0.5^{(*)}$ \\
\hline
\end{tabular}

(*) $<0.5$ according to author

below, between and above the two boundaries, where the soils with: low activity, medium activity and high activity should lie, respectively. The author's activity classification differs from that proposed by Skempton (1953). The term "low" activity replaces the term "inactive" because it appears to be more suitable for distinguishing the nonplastic soils (not plotted on the chart). Note that a soil with a liquid limit greater than $100 \%$ (Fig. 2) can be classified as an "inactive" clay, according to Skempton's classification. In Fig. 2, the zone where the soils with medium activity should lie (located between bounds $A=$ 0.75 and $A=1.25$ ) is rather narrow compared with the low and high activity zones and no particular physical significance appears attributable to the boundaries adopted. In agreement with the range of values of the clay minerals shown in Table 2, two boundaries for the lowest activity values might be more useful (also to distinguish the sliding shear behaviour of clays, see below). On the activity chart (Fig. 3) such bounds, termed L-line and $\mathrm{H}$-line, are proposed for the values $A=0.5$ (which is the value of a subgroup noted by Skempton, 1953) and $A=1.0$, respectively. Hence, soils containing mostly kaolinite and montmorillonite clay minerals (regardless of the clay percentage they contain) should lie in the low activity zone and in the high activity zone, respectively.

\section{ACTIVITY CHART}

On the basis of the interdependence of the parameters $W_{\mathrm{L}}, W_{\mathrm{p}}, I_{\mathrm{p}}, A$ and $C F$, it seems appropriate to classify the inorganic soils with platey clay minerals according to both their clay size content and activity. Figure 3 shows the activity chart which classifies soils using the Atterberg limits. The difference between this chart and Polidori's plasticity chart (Fig. 1) lies in the two new boundaries that define three zones with different ranges of activity values (instead of boundary at $W_{\mathrm{L}}=50 \%$, according to the ASTM standard, D 2487).

All the plasticity index values of the inorganic soils with platey clay minerals and $C F<100 \%$ should lie above the $\mathrm{C}$-line and the distance of the points from the $\mathrm{C}$-line should be inversely proportional to clay percentage of the respective soils. The $0.5 \mathrm{C}$-line allows us to distinguish the points that fall below the line, clays $(\mathrm{C})$, from the points lying above the line in the silt zone (M). The clay zone is found between the $\mathrm{C}$-line and the $0.5 \mathrm{C}$-line and inorganic soils with $C F \geq 50 \%$ should be found here. The silt zone is located between the $0.5 \mathrm{C}$-line and the U-line and inorganic soils composed of silt and/or sand $(2-425 \mu \mathrm{m})>50 \%$ should lie here. The L-line and the $\mathrm{H}$-line (for $A=0.5$ and 


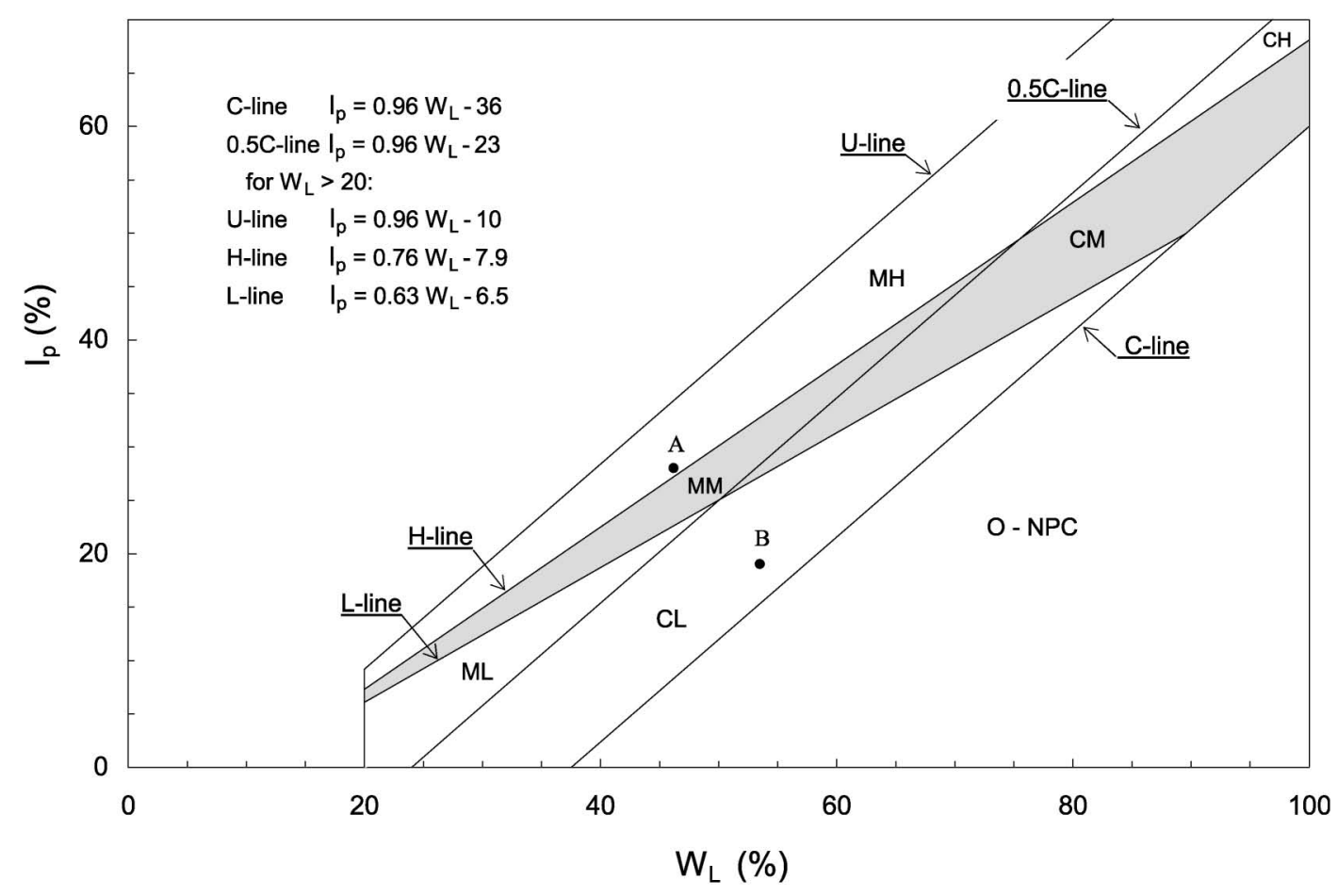

Fig. 3. Activity chart. $\mathrm{C}$-line, $0.5 \mathrm{C}$-line: lines on which plasticity index, $I_{\mathrm{p}}$, values should lie as a function of liquid limit, $W_{\mathrm{L}}$, of inorganic soils (with platey clay minerals) that contain $100 \% C F$ and $50 \% C F(<2 \mu \mathrm{m})$ respectively. U-line: upper limit of existence of soils. H-line, L-line: lines on which $I_{\mathrm{p}}$ values should lie (against $W_{\mathrm{L}}$ ), of inorganic soils with 1.0 and 0.5 values of activity, respectively. CL, CM, CH $=$ groups of clays $(C F \geq 50 \%)$ with low, medium and high activity, respectively. ML, MM, MH $=$ groups of silts $(2-425 \mu \mathrm{m}>50 \%)$ with low, medium and high activity, respectively. $O=$ organic soils. $N P C=$ soils with non-platey clay minerals. $(A$ and B: soils data from Fig. 1)

$A=1.0$, respectively) subdivide the silt and clay zones into three groups: low activity (L), medium activity (M) and high activity $(\mathrm{H})$, located, below, between and above the two boundaries, respectively.

The residual inorganic soils (NPC) composed of nonplatey clay minerals (allophane, halloysite, attapulgite) should lie below the $\mathrm{C}$-line because their characteristics (high plastic limit, low plasticity index, high residual strength, etc.; Kenney, 1967; Wesley, 1973; Skempton, 1985; Mitchell, 1993; Rao, 1996; So, 1998) are very different from those of platey clay minerals for which the activity chart was developed. The soils (NPC) that contain both platey and non-platey clay minerals as well as the organic soils $(\mathrm{O})$ can lie above or below the $\mathrm{C}$-line according to characteristics and proportions of the soil constituents.

Characterizing the soils containing non-platey clay minerals is not always easy, and estimating both the contents (if present) of platey and non-platey clay minerals in the same soil is impossible in routine assessments of soil properties. Nevertheless, even if the non-platey clay minerals in the clay fraction of a soil are not identified as such, in engineering problems their presence makes the soil "safer" because the intrinsic mechanical properties of residual clay minerals (e.g., the residual friction angle) are better than those of the platey clay minerals.

From a behavioural standpoint, an organic soil contains sufficient organic matter to influence the liquid limit (and other soil properties). Hence, if a soil shows the distinctive characteristics of an organic substance (such as: dark colour, characteristic smell when moist and warm, reacts to hydrogen peroxide, etc.). a second liquid limit test should be performed on a soil specimen which has been oven dried at $105^{\circ} \mathrm{C}$. It will be classified as an organic soil if the liquid limit after oven drying is less than $95 \%$ of the liquid limit determined before oven drying. Further study and new experimental data are desirable to understand which value is more suitable: the proposed value $(95 \%)$ or a lesser value (e.g., $90 \%)$. Note that the Atterberg limits of both soil types (O-NPC) are not governed by $C F$ linear law. Hence, their plastic limit can be determined only through the $W_{\mathrm{p}}$ standard test (and not using Eq. (5), see below).

The possible distinction (low and high plasticity, not shown in Fig. 3) for soils that lie below the C-line could be more useful based on the plasticity index value rather than on the liquid limit value.

Applying the proposed classification method, for example, plotting the data of the two soils shown in Fig. 1 in Fig. 3, soil A is classified as a "silt with high activity" instead of a "silt with low plasticity" and soil B is classified as a "clay with low activity" instead of a "clay with high plasticity".

\section{Soils containing only Platey Shape Clay Minerals}

The Atterberg limits governed by linear law to $C F$ are of fundamental importance in characterizing and obtaining correlations with the intrinsic mechanical properties of soils because they show the soil's behaviour dominated by the clay phase. On the contrary, when the volume of the clay water system in a sample soil is equal to or lesser 
than the volume of the voids of the non-clay phase (when the non-clay particles are in contact with one another due to low $C F$ in the soil-water system) the Atterberg limits-if determinable-are no longer ruled by $C F$ linear law because the behaviour of the soil is dominated by the granular phase characteristics.

It may not be a simple task to determine the soil's physical state because the determination of the void ratio of the fraction $>2 \mu \mathrm{m}$ of a soil (necessary to estimate the voids' volume in the granular phase) is cumbersome and time consuming. Nevertheless, if the clay percentage in the soil fraction passing the No. $40(<425 \mu \mathrm{m})$ sieve is low $(C F<25-30 \%)$, the Atterberg limits can to be performed on a soil fraction with a diameter that is less than that passing the No. 40 sieve. Hence the Atterberg limit values that should correspond to the clay percentage of the soil passing the No. 40 sieve (and for any other $C F$ ) can be appraised (using Eqs: $W_{\mathrm{L}}=k_{1} C F$ and $W_{\mathrm{p}}=\left(k_{2} C F\right)$ +10 , where $k_{1}$ and $k_{2}$ are the slopes).

It is known that every measured data has some margin of error. In fact, the interrelationship among the parameters $W_{\mathrm{L}}, W_{\mathrm{p}}, I_{\mathrm{p}}, A$ and $C F$ (on which the proposed chart is based) was obtained on the basis of the average values (using the equations of the regression lines) of the Atterberg limits governed by $C F$ linear law (performed according to ASTM standards, D 4318 and D 422). The quantitative relationship with respect to the plastic limit is:

$$
W_{\mathrm{p}}=0.04 W_{\mathrm{L}}+(0.26 C F+10)
$$

Equation (5) can replace the $W_{\mathrm{p}}$ standard test if the values linearly proportional to the $W_{\mathrm{L}}$ and $C F$ of the tested soil are known.

Since the parameters are linked with one another, at a given $W_{\mathrm{L}}$ value (on the activity chart), the $W_{\mathrm{p}}$ measured value (through $I_{\mathrm{p}}$ ), the activity value and the value of the percentage of clay of the tested soil $<425 \mu \mathrm{m}$ should correspond. Hence this value of $C F$, appreciable on the chart (or analytically calculable), should be (approximately) equal to the clay percentage of the grain size distribution of the soil fraction $<425 \mu \mathrm{m}$ used in the Atterberg limits test. If the difference between the measured and calculated values is considerable, it would be useful to understand the causes of the discrepancy (e.g., standard tests performed incorrectly, the presence of non-platey clay minerals in the sample soil tested, etc.).

In Figs. 4, 5, 6 and 9 both the values of the plasticity index (measured and calculated) being compared are plotted. In Figs. 6 and 9 the calculated values of $I_{\mathrm{p}}$ are based on the $C F$ value reported by the authors, assuming that both the clay contents of the entire soil and the soil used for the Atterberg limits test are equal.

Considering: (i) the poor precision of the standard method for determining the plastic limit (Whyte, 1982; Polidori, 2007) and, (ii) the link between $W_{\mathrm{p}}$ and $C F$ in Eq. (5) (an error of $10 \%$ on the $C F$ value produces an error of 2.6 units on the $W_{\mathrm{p}}$ value, or vice versa), it is possible to assert that the measured values of $W_{\mathrm{L}}$ and $C F$ (linearly proportional) of the soil tested (to obtain $W_{\mathrm{p}}, I_{\mathrm{p}}$ and $A$ ) are more suitable than the measured values of $W_{\mathrm{L}}$ and $W_{\mathrm{p}}$ (to obtain $C F, I_{\mathrm{p}}$ and $A$ ). It is evident that (among the measurable parameters $W_{\mathrm{L}}, W_{\mathrm{p}}, C F$ ), the liquid limit test is of fundamental importance. Casagrande's method for determining the liquid limit is an easy reproducible test. For example, Sridharan et al. $(1986,1988)$ reported that the variation between two trials was about $1 \%$.

\section{EXAMPLES OF SOILS PLOTTED ON THE ACTIVITY CHART}

In Fig. 4 the values of the plasticity index (measured and calculated) are plotted as a function of the liquid limit of the pure clay mineral kaolinite, bentonite and their mixtures as shown in Table 3. Since all of the mixtures are composed of $100 \%$ clay, all the respective values of the plasticity index should lie on the C-line (regardless of any possible chemical interaction among the constituents). Pure kaolinite and the mixture with $75 \%$ kaolinite lie in the low activity clay zone and medium activity clay zone, respectively, whereas the other mixtures with $50 \%$ or more bentonite lie in the high activity clay zone. The same mixtures plotted on the plasticity chart (Fig. 1) would all lie in the high plasticity clay zone. As expected, values of residual soils (with non-platey clay minerals) lie below the C-line independently of their clay percentage.

Figure 5 shows the data of the clay minerals illite (with

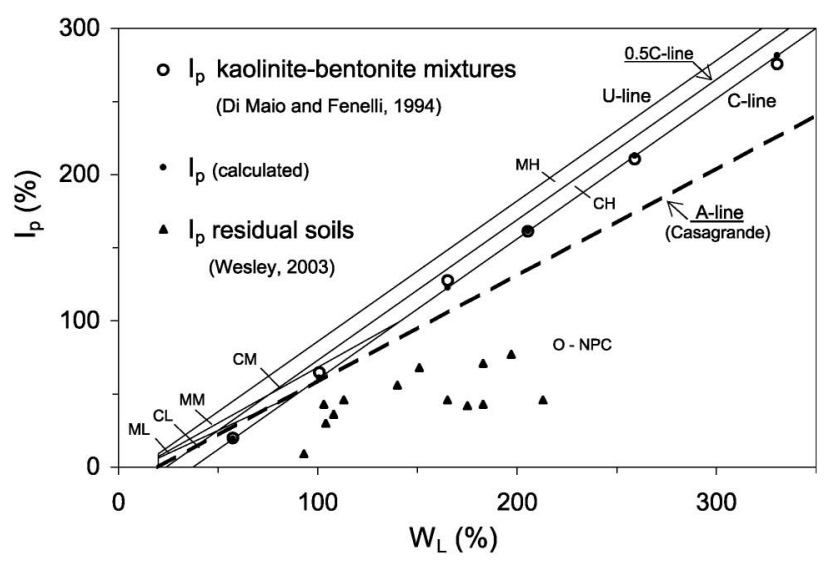

Fig. 4. Location on proposed activity chart (see Fig. 3) of data from literature (Table 3). Casagrande's A-line also shown

Table 3. Index properties of clay minerals $(K=$ kaolinite; $B=b e n-$ tonite) and their mixtures, from Di Maio and Fenelli (1994). $I_{\mathrm{p}}(\mathrm{c})=$ plasticity index calculated with Eq. (1)

\begin{tabular}{ccrrr}
\hline Soil & $C F$ & $W_{\mathrm{L}}$ & \multicolumn{1}{c}{$I_{\mathrm{p}}$} & $I_{\mathrm{p}}(\mathrm{c})$ \\
\hline K & 100 & 57.5 & 19.7 & 19.2 \\
$75 \% \mathrm{~K}-25 \% \mathrm{~B}$ & 100 & 100.9 & 63.5 & 60.9 \\
$50 \% \mathrm{~K}-50 \% \mathrm{~B}$ & 100 & 165.3 & 127.5 & 122.7 \\
$40 \% \mathrm{~K}-60 \% \mathrm{~B}$ & 100 & 205.5 & 161.2 & 161.3 \\
$25 \% \mathrm{~K}-75 \% \mathrm{~B}$ & 100 & 259.2 & 210.3 & 212.8 \\
B & 100 & 330.6 & 275.4 & 281.4 \\
\hline
\end{tabular}

$C F=(\%<2 \mu \mathrm{m}) ; W_{\mathrm{L}}$ and $I_{\mathrm{p}}$ are in $\%$ 


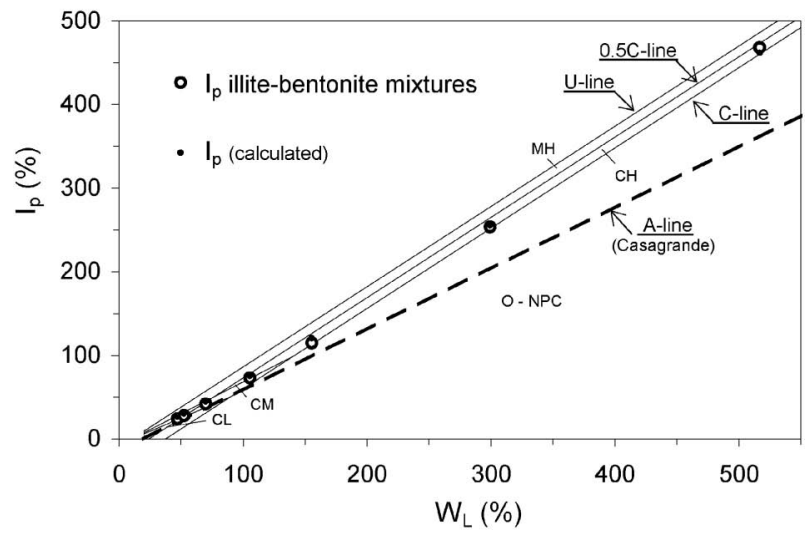

Fig. 5. Location on proposed activity chart (see Fig. 3) of data from Seed et al. (1964). $I_{\mathrm{p}}$ calculated with Eq. (1) and Casagrande's Aline also shown

Table 4. Index properties of natural soils taken from Lupini et al. (1981). $I_{\mathrm{p}}$ (c) and $A$ (c), values calculated with Eqs. (1) and (2) respectively

\begin{tabular}{|c|c|c|c|c|c|c|}
\hline Soil no. & $C F$ & $W_{\mathrm{L}}$ & $I_{\mathrm{p}}$ & $I_{\mathrm{p}}(\mathrm{c})$ & $A$ & $A$ (c) \\
\hline 1 & 55 & 71 & 43 & 44 & 0.78 & 0.80 \\
\hline 2 & 43 & 59 & 31 & 35 & 0.72 & 0.81 \\
\hline 3 & 50 & 57 & 33 & 32 & 0.66 & 0.64 \\
\hline 4 & 32 & 26 & 6 & 6 & 0.19 & 0.19 \\
\hline 5 & 32 & 31 & 12 & 12 & 0.37 & 0.37 \\
\hline 6 & 52 & 65 & 33 & 39 & 0.63 & 0.75 \\
\hline 7 & 63 & 63 & 35 & 34 & 0.55 & 0.54 \\
\hline 8 & 47 & 59 & 33 & 34 & 0.70 & 0.72 \\
\hline 9 & 50 & 59 & 29 & 34 & 0.58 & 0.68 \\
\hline 10 & 51 & 63 & 37 & 37 & 0.73 & 0.73 \\
\hline 11 & 48 & 75 & 51 & 50 & 1.06 & 1.04 \\
\hline 12 & 48 & 73 & 49 & 48 & 1.02 & 1.00 \\
\hline 13 & 36 & 57 & 36 & 36 & 1.00 & 1.00 \\
\hline 14 & 57 & 72 & 43 & 44 & 0.76 & 0.77 \\
\hline 15 & 59 & 95 & 61 & 66 & 1.03 & 1.12 \\
\hline 16 & 57 & 82 & 54 & 54 & 0.95 & 0.95 \\
\hline 17 & 53 & 66 & 42 & 40 & 0.79 & 0.75 \\
\hline 18 & 64 & 68 & 43 & 39 & 0.67 & 0.61 \\
\hline 19 & 46 & 62 & 36 & 38 & 0.78 & 0.82 \\
\hline 20 & 50 & 85 & 58 & 58 & 1.16 & 1.16 \\
\hline 21 & 52 & 58 & 32 & 32 & 0.62 & 0.62 \\
\hline 22 & 51 & 59 & 36 & 33 & 0.71 & 0.65 \\
\hline 23 & 60 & 93 & 61 & 64 & 1.02 & 1.07 \\
\hline 24 & 50 & 94 & 60 & 67 & 1.20 & 1.34 \\
\hline 25 & 38 & 41 & 20 & 20 & 0.53 & 0.53 \\
\hline 26 & 46 & 63 & 38 & 38 & 0.83 & 0.83 \\
\hline
\end{tabular}

$C F=(\%<2 \mu \mathrm{m}) ; W_{\mathrm{L}}$ and $I_{\mathrm{p}}$ are in $\%$

$C F=35 \%$ ), bentonite (with $C F=95 \%$ ) and their mixtures (Seed et al., 1964). The $I_{\mathrm{p}}$ values of the illite and mixtures (containing 95\% and 80\% illite) with $C F<50 \%$ lie in the medium activity silt zone, whereas data of the mixtures with the highest bentonite content (and $C F>50$ $\%)$ lie in the high activity clay zone. The same soils plotted on the plasticity chart (Fig. 1) would lie in the high plasticity clay zone, except illite which would lie in the low plasticity silt zone.

Table 4 shows the data (including the calculated values of $I_{\mathrm{p}}$ and $A$ ) of natural soils (except the soils with $C F<30$

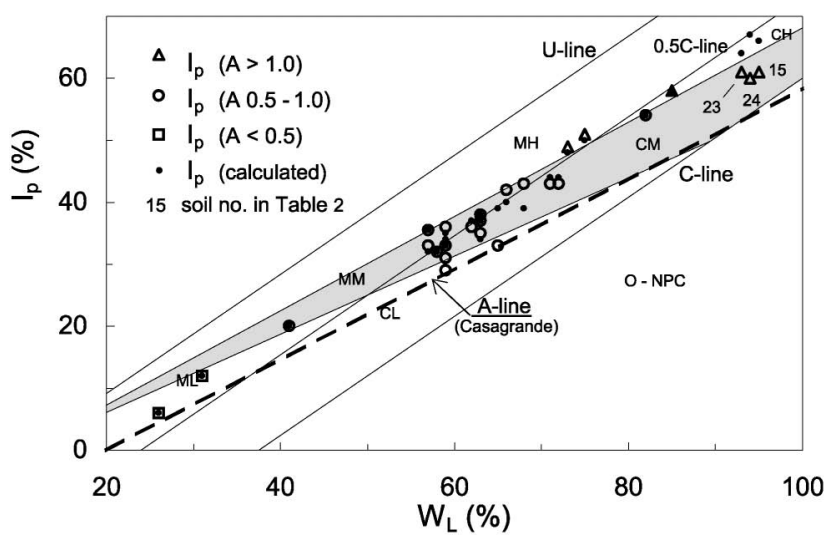

Fig. 6. Location on proposed activity chart (see Fig. 3) of natural soils shown in Table 4. $I_{\mathrm{p}}$ calculated with Eq. (1) and Casagrande's A-line also shown. $A=$ activity

$\%$ and the residual soils) taken from Lupini et al. (1981). These soils are plotted in Fig. 6 where they are subdivided into three groups as a function of their measured activity values. The soils with measured plasticity index values which are different from those calculated with Eq. (1), have clay percentages (appreciable on the graph or analytically calculable with equation: $C F=\left[\left(0.96 W_{\mathrm{L}}-I_{\mathrm{p}}\right)-\right.$ 10]/0.26 obtained from Eq. (1)) which differ from those reported by the authors. Hence, some soils may lie in a zone that does not correspond to their $C F$ and/or their activity value. For example, soils no. 15, 23 and 24 have activity values that are greater than 1 and therefore should not lie in the medium activity clay zone (of grey color).

For 21 soils (of the 26 soils plotted) the difference between both the activity values (Table 4) is rather small (average value $<0.02$ ). If both the clay fractions are equal (of the entire soil and the soil $<425 \mu \mathrm{m}$ used for the Atterberg limits test) and organic substances and nonplaty clay minerals are absent, the causes of the discrepancy between the ( $I_{\mathrm{p}}$ and $A$ ) measured and calculated values may be mainly attributable to the poor precision of the standard method for determining the plastic limit.

In Figs. 4-6 the A-line $\left(I_{\mathrm{p}}=0.73\left(W_{\mathrm{L}}-20\right)\right.$; Casagrande, 1948) has also been included in order to show where the same soils (of different types) would lie on Casagrande's plasticity chart, since the respective positions of the silt and clay zones appear reversed on the two charts. Only the data of the residual soils (Fig. 4) containing non-platey clay minerals and (amiss) kaolinite fall below the A-line in Casagrande's silt zone. The position of the A-line is such that the common inorganic soils (containing platey clay minerals), except relatively pure kaolinite, lie above it in the clay zone regardless of their clay percentage. In fact, in a previous paper (Polidori, 2007) of 125 soil samples plotted, only 3 kaolinite soils lie below the A-line in the silt zone (according to Casagrande). The same occurs, for example, in the paper by Nagaraj and Jayadeva (1983) where 520 soil samples are plotted on Casagrande's plasticity chart. All soils lie above the A-line in the clay zone, except for the data of 3 
soils that lie below the A-line in Casagrande's silt zone. Hence, it is evident that the boundary A-line is equivalent to Polidori's C-line because the residual soils lie below both the boundaries. It therefore appears more accurate to affirm that on the empirical plasticity chart proposed by Casagrande, no distinction (silt zone) exists above the A-line where the common soils lie. In essence (since the behaviour of a soil, in addition to the type of clay minerals, etc., also depends on the clay percentage), it can be concluded that Casagrande's chart does not suffice to classify and predict engineering behaviour (such as residual shear behaviour) of soils containing platey clay minerals.

\section{ACTIVITY CHART TO PREDICT RESIDUAL SHEAR BEHAVIOUR OF COHESIVE SOILS}

Correlations making use of the index properties are fairly common in soil mechanics literature, especially to estimate the compression index and drained residual strength friction angle, $\varphi_{\mathrm{r}}^{\prime}$ of fine-grained soils. In addition, the proposed activity chart can be useful for this purpose. The activity chart adapted to estimate the drained residual shear behaviour of inorganic soils containing platey clay minerals is shown herein. Clearly, the following considerations are not valid for non-platey clay minerals (halloysite, allophone, attapulgite) that exhibit residual friction angles close to that of round particles, usually greater than $25^{\circ}$ (Kenney, 1967; Wesley, 1977).

Various attempts have been made to correlate the residual strength friction angle of cohesive soils with their index properties such as the liquid limit, plasticity index, activity and clay fraction (Skempton, 1964, 1985; Kenney, 1967, 1977; Voight, 1973; Kanji, 1974; Seycek, 1978; Vaughan et al., 1978; Lupini et al., 1981; Mesri and Cepeda Diaz, 1986; Collotta et al., 1989; Stark et al., 1994; Wesley, 2003; Dewoolkar and Huzjak, 2005; and others).

Skempton (1985) investigated the drained residual strength of some English clays and compared field and laboratory values, contributing a valuable update on residual shear strength and supporting the three residual shear behaviours shown by Lupini et al. (1981). The main points carried out by Skempton are as follows:

- Residual friction angle of a soil (for a given normal effective pressure) depends on its clay percentage and type (activity) of platey clay mineral (Fig. 7). Specifically, if the clay fraction in a soil is less than about 25 $\%$, the soil behaves much like a sand or silt with angles of residual shearing resistance typically greater than $20^{\circ}$ (Rolling shear). Conversely, when the clay fraction in a soil is about $50 \%$, residual strength is controlled almost entirely by sliding friction of the platey clay minerals (Sliding shear), and further increase in $C F$ has little effect. When the clay fraction lies between $25 \%$ and $50 \%$, there is a Transitional shear involving both rolling and sliding shear mechanisms in different parts of a shear zone.

- For most soils the relation between residual strength

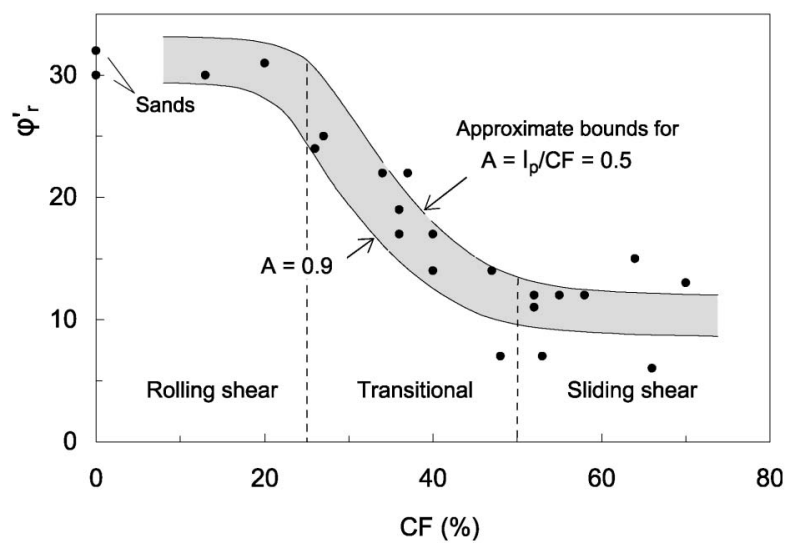

Fig. 7. Dependence of residual friction angle, $\varphi_{\mathrm{r}}^{\prime}$ by clay fraction, $C F$ and activity, $A$, according to Skempton (1985). $\varphi_{\mathrm{r}}^{\prime}-C F$ data of samples plotted in Figs. 8 and 9 also shown

and normal effective pressure is non-linear and the variation in the degree of curvature between one soil and another can be considerable.

In Fig. 8 three zones that correspond to three cited modes of residual shearing behaviour: Rolling shear, Transitional shear and Sliding shear (from U-line to Cline, respectively) are shown. In turn, the sliding shear zone is subdivided into three sub-zones (as a function of the range of the activity values) as shown on the activity chart. The boundaries that define the transitional zone are according to Eq. (1). The average values of the clay percentage $(C F=25 \%$ and $C F=45 \%)$ which define such a range, are in agreement with Skempton (1985) and the author's study in progress. The residual friction angle range values expected for the soils that lie in these zones and sub-zones (where $\varphi_{\mathrm{r}}^{\prime}=12^{\circ}-15^{\circ}$ and $\varphi_{\mathrm{r}}^{\prime}=4^{\circ}-10^{\circ}$ are expected for soils containing mainly kaolinite and montmorillonite clay minerals, respectively (Skempton, 1985; Mitchell, 1993)) are also shown.

From Fig. 8 it can be inferred that, for soils with the same $I_{\mathrm{p}}$ value, $\varphi_{\mathrm{r}}^{\prime}$ is expected to decrease as $W_{\mathrm{L}}$ increases (from rolling shear to sliding shear zones) and for soils with the same $W_{\mathrm{L}}$ value, $\varphi_{\mathrm{r}}^{\prime}$ is expected to increase as $I_{\mathrm{p}}$ increases (from sliding shear to rolling shear zones). Hence, it is obvious that the correlations based on either $W_{\mathrm{L}}$ or $I_{\mathrm{p}}$ do not provide good estimates of the drained residual friction angle. The correlation $\varphi_{\mathrm{r}}^{\prime}-C F$ seems more appropriate than $\varphi_{\mathrm{r}}^{\prime}-I_{\mathrm{p}}$ (and $\varphi_{\mathrm{r}}^{\prime}-W_{\mathrm{L}}$ ), but is not enough to obtain reliable $\varphi_{\mathrm{r}}^{\prime}$ values for engineering purposes.

The drained residual strength behaviour is strongly dependent on the distance among the round particles contained in a soil. Specifically, in a normal consolidated soil at a given normal effective pressure, this distance is mainly a function of the amount and type of platey clay minerals (chemical state enclosed) and of the granular phase void ratio. When both the volume of the clay-water system and that of the voids of the granular phase are equal, the non-clay particles are in contact with one another.

The characteristics of the soil granular phase (such as the void ratio, size-shape of the particles, gradation, etc.) 


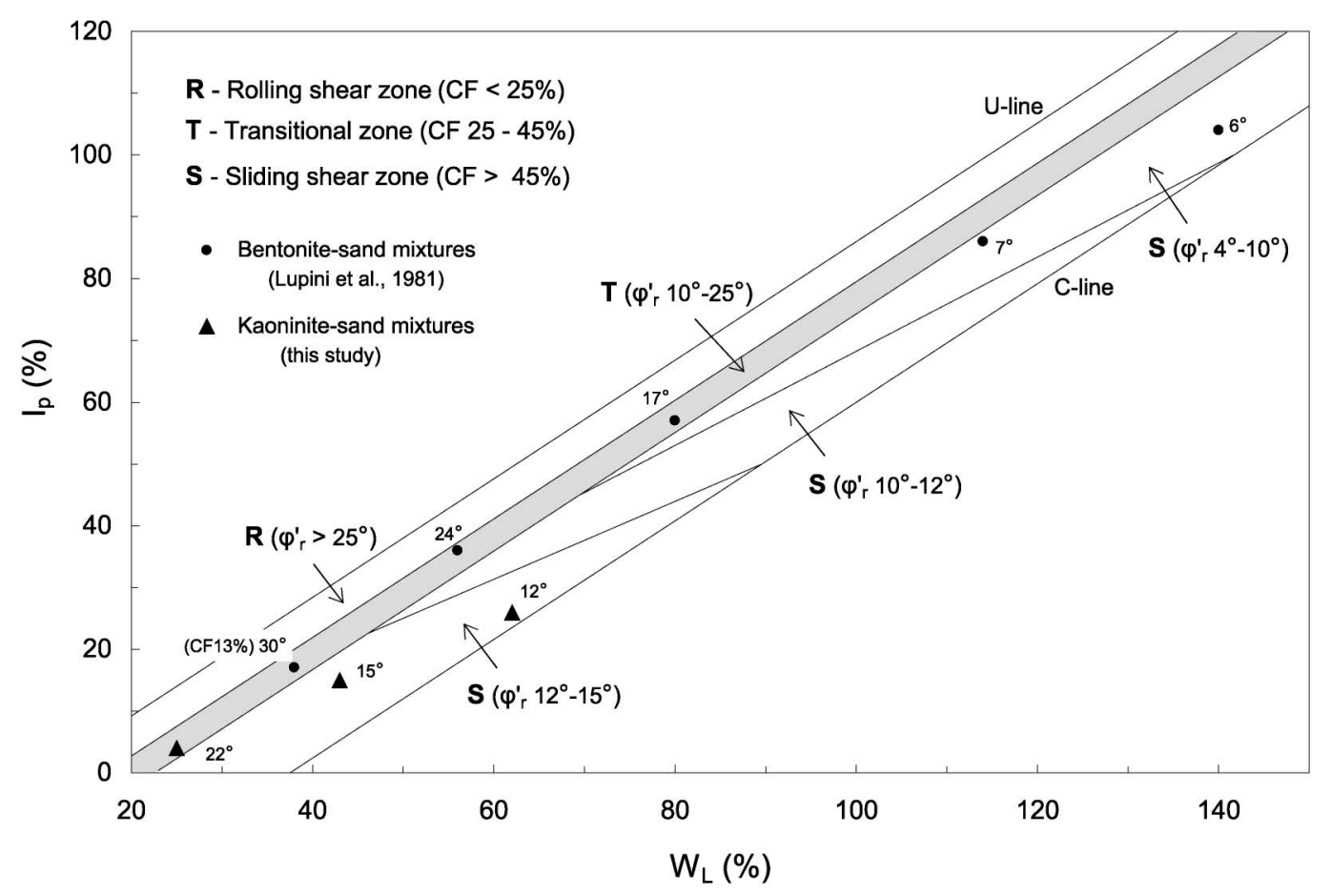

Fig. 8. Activity chart adapted to predict residual shear behaviour of cohesive soils containing platey clay minerals. Mixtures of bentonite-sand and kaolinite-sand are also shown. The $I_{\mathrm{p}}-W_{\mathrm{L}}$ values belonging to bentonite-sand mixture with the lowest $C F$ value $\left(C F=13 \%, \varphi_{\mathrm{r}}^{\prime}=30^{\circ}\right)$ should not lie on transitional zone (see text). $\varphi_{\mathrm{r}}^{\prime}\left(24^{\circ}\right)=$ drained residual friction angle (value in degrees)

and their effect on $\varphi_{\mathrm{r}}^{\prime}$, cannot be known through the Atterberg limit values. Nevertheless, plotting the $\left(I_{\mathrm{p}}-W_{\mathrm{L}}\right)$ data of soils in Fig. 8, a reduction in residual friction angle with the increase of the clay percentage from that of a soil involving rolling shear without preferred particles orientation (high $\varphi_{\mathrm{r}}^{\prime}$ ), to that of pure platey clay minerals, involving sliding shear (low $\varphi_{\mathrm{r}}^{\prime}$ ), is expected. In turn, in the sliding shear zone (that contains the soils in which the round particles are scattered in the clay-water system), the more active the clay fraction, the lower the residual friction angle at a given clay percentage and a given confining pressure.

In conclusion, for the common inorganic soils $(<425$ $\mu \mathrm{m})$, the plotting of the Atterberg limits data on the activity chart allows us to make a better appraisal of the residual shear behaviour than the predicted correlations. This is because the residual shear strength is related to all the interdependent parameters $\left(W_{\mathrm{L}}, I_{\mathrm{p}}, A\right.$ and $\left.C F\right)$ on which the chart is based.

It is worth noting that the same sample preparation procedure (standard) and the same apparatus (direct shear box or ring shear tests) should be used to better compare (or develop correlations between) property data of soils. In addition, both the clay fractions (of the sample used for residual shear test and of that used for Atterberg limit test) should be equal (both passing the No. 40 ASTM sieve) to obtain methodically accurate relations.

In Fig. 8, the Atterberg limits of the mixtures of bentonite-sand and kaolinite-sand are plotted with the relative residual friction angle values $\left(\varphi_{\mathrm{r}}^{\prime}=\tan ^{-1}\left(\tau_{\mathrm{r}}^{\prime} / \sigma^{\prime}\right)\right.$, where $\tau_{\mathrm{r}}^{\prime}$ is the residual strength at a normal effective pressure, $\sigma^{\prime}=350 \mathrm{kPa}$ ). Direct shear box and ring shear tests were used for kaolinite and bentonite, respectively. Note when in a sample soil the non-clay particles are in contact with one another (rolling shear behaviour should occur) and the Atterberg limits values are no longer ruled by the $C F$ linear law because the behaviour of the soil is dominated by the granular phase characteristics. Hence soils found in this physical state can lie within rolling shear zone or below in the transitional zone. This is shown in Fig. 8 for the bentonite-sand mixture which is characterized by the lowest clay fraction $\left(C F=13 \%, \varphi_{\mathrm{r}}^{\prime}=30^{\circ}\right)$. The residual friction angle values of the remaining mixtures are in good agreement with those of the zones on which the data lie.

Figure 9 shows the index properties and $\varphi_{\mathrm{r}}^{\prime}$ values of some English clays and of Happisburgh clay-London clay mixtures (normally consolidated at $\sigma^{\prime}=150 \mathrm{kPa}$ and $\sigma^{\prime}$ $=350 \mathrm{kPa}$, respectively) taken from literature. Direct shear box for the English clays and ring shear tests for the cited mixtures, were used. It can be observed that, the $\varphi_{\mathrm{r}}^{\prime}$ values are in better agreement with the location of the $I_{\mathrm{p}}$ calculated values rather than the location of the $I_{\mathrm{p}}$ measured values. This confirms the validity of the quantitative interrelationship proposed.

Correlations to obtain a reliable value of $\varphi_{\mathrm{r}}^{\prime}$ from index properties of a soil should not be tenable for two main reasons (regardless of the procedure and apparatus used): (i) the different role played by the granular phase (that is a passive role of inert fill in the Atterberg limits test), (ii) the influence of normal effective stress acting on the shear zone. As a consequence, soils with the same Atterberg limit values (linearly proportional to $C F$ ) can show different $\varphi_{\mathrm{r}}^{\prime}$ resulting from their granular phase characteristics 


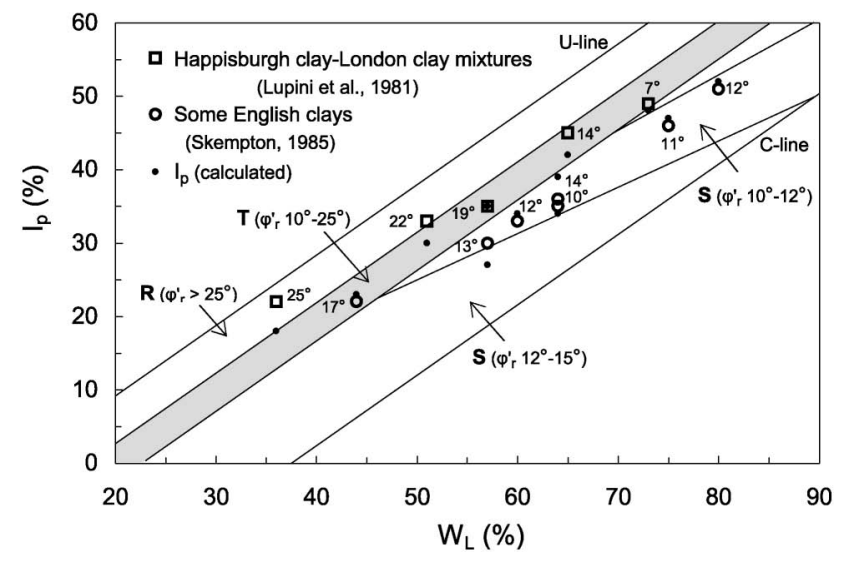

Fig. 9. Location on the adapted activity chart to predict residual shear behaviour ( $s e e$ Fig. 8) of natural soils. $R$, $T$ and $S=$ Rolling, Transitional and Sliding shear zones, respectively. $\varphi_{\mathrm{r}}^{\prime}\left(1^{\circ}\right)=$ drained residual friction angle (value in degrees). $I_{\mathrm{p}}$ calculated with Eq. (1) also shown

(particularly for soils that lie in transitional zone) and/or from normal stress acting on their failure plane. In addition, more values of $\varphi_{\mathrm{r}}^{\prime}$ can also correspond to a single soil as a function of the confining pressure applied. Indeed, Skempton (1985) suggested that it is better to compare soils' $\varphi_{\mathrm{r}}^{\prime}$ values achieved at the same pressure. This means that, in terms of $C F$, the range of the transitional zone depends on both the granular phase characteristics and the normal stress. Nevertheless, the location of soils data $\left(I_{\mathrm{p}}-W_{\mathrm{L}}\right)$ on the activity chart is useful for understanding the corresponding residual shear behaviour and the expected range of $\varphi_{\mathrm{r}}^{\prime}$ values. The activity chart used for this purpose should not replace site-specific laboratory determination of residual shear strength. Instead, it can be useful in selecting samples for laboratory residual strength tests. If the difference between both the residual friction angle values (the experimental value and that which is inferred from the range on the activity chart) is noticeable, it would be better to understand the causes of the discrepancy (e.g., presence of particles $>425 \mu \mathrm{m}$ in the sample for residual shear test or the presence of nonplatey clay minerals; partial disruption of the samples on which the index tests were performed, sometimes such disruption can increase during the shear displacement and platey clay particles may be generated; etc.).

Further study and new experimental data are necessary to understand the meaning of the different degree of curvature of the residual shear envelope between one soil and another.

\section{FINE AND COARSE SOILS CLASSIFICATION}

In order to classify soils, according to the current ASTM standard (D 2487), the distinction between coarsegrained soils and fine-grained soils is based on the percentage by dry weight ( $<50 \%$ and $\geq 50 \%$, respectively) of the test specimen passing the No. $200(75 \mu \mathrm{m})$ sieve. Coarse-grained soils are classified primarily by grain size

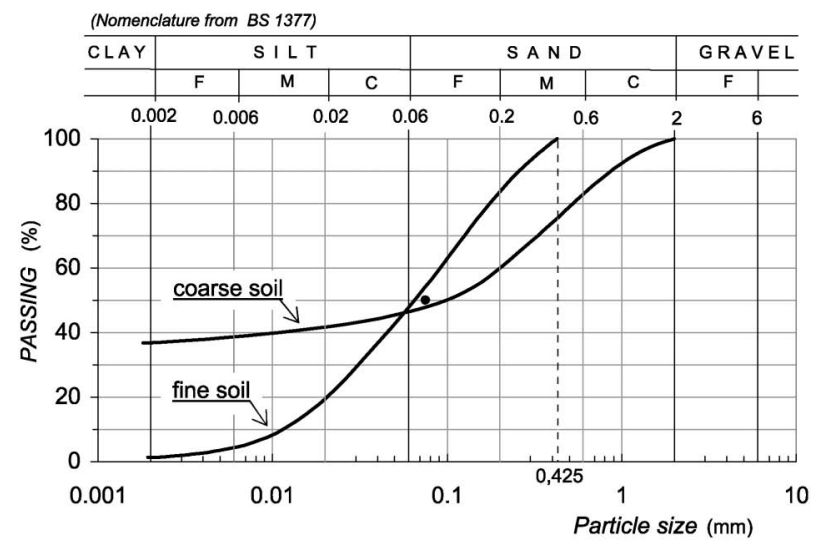

Fig. 10. Example of grain size distribution of two soils classified according to ASTM standard (D 2487). The soils with the granulometric curves that lie above and below the point plotted are classified as fine-grained and coarse-grained soils, respectively. The finegrained soil, with a very low clay fraction, can not be characterized with the predicted plasticity tests

distribution of particles $>75 \mu \mathrm{m}$ (sand or gravel whichever is predominant), while fine-grained soils are classified primarily by plasticity characteristics of the soil fraction $<425 \mu \mathrm{m}$.

Hence, a soil with a high percentage ( $>50 \%$ ) of particles passing the No. 200 sieve and a very low (or absent) clay percentage is classified as a "fine-grained soil," whereas its behaviour should be (not plastic, similar to that expected for coarse-grained soils) dominated by the characteristics of the non-clay size particles. The contrary can occur when in a coarse soil the percentage of the nonclay particles $(2-75 \mu \mathrm{m})$ is very low and the clay percentage is relatively high. Figure 10 shows an example of possible grain-size distribution of fine and coarse soils as described above. Note that a fine soil with the clay fraction absent or very low (such as the fine soil shown in Fig. 10) cannot be characterized using the predicted Atterberg limits. In addition, if a soil is composed only of silt particles, it cannot be classified following fine-grained soils procedure (Atterberg limits) or coarse-grained soils procedure (sieves). This can also occur using other standards.

Since the behaviour of a soil (in addition to the type of clay minerals, etc.) also depends on the clay percentage, the distinction between coarse soils and fine soils based on their percentage of clay $(<2 \mu \mathrm{m})$, might be more useful. The percentage of clay in a soil is an important parameter. For example, Skempton $(1964,1985)$ concluded that there is better correlation between the residual friction angle and the clay percentage of a soil rather than its Atterberg limits. The author's opinion is that both the clay percentages (of the fraction $<425 \mu \mathrm{m}$ and of the entire soil) together with the Atterberg limits are of importance in order to characterize inorganic soils with platey clay minerals and to obtain correlations with the intrinsic mechanical properties of the soils. Note that for common inorganic soils, the clay percentage can be appraised without performing the hydrometer analysis of 
the test sample. Specifically, from Atterberg limits of a soil, the clay percentage of the tested soil $(<425 \mu \mathrm{m})$ can be analytically calculated (or graphically estimated plotting Atterberg limits data on the activity chart). The clay percentage of the entire soil can then be determined, if the percentage of the soil retained on the No. $40(425 \mu \mathrm{m})$ sieve, which is excluded from Atterberg limits characterization, is known.

The alternative way (more laborious but more appropriate) is: knowing only $W_{\mathrm{L}}$ and $C F$ (linearly proportional) of the soil tested, the $W_{\mathrm{p}}, I_{\mathrm{p}}$ and $A$ values can be calculated.

\section{CONCLUSIONS}

The proposed activity chart $\left(W_{\mathrm{L}}, I_{\mathrm{p}}\right)$, which aims to classify soils (or their fraction) $<425 \mu \mathrm{m}$ using the Atterberg limits, differs from the plasticity chart previously proposed by the author because the inorganic soils with platey clay minerals are classified (in addition to clay percentage) on the basis of their activity rather than on their plasticity (low or high plasticity when the liquid limit value is less than or greater than $50 \%$ respectively, according to ASTM standard). Hence, the activity chart proposed (based on the interdependence among the parameters, $W_{\mathrm{L}}, W_{\mathrm{p}}, I_{\mathrm{p}}, A$ and $C F$ of the tested soil), appears more suitable because the classification (silt and clay, in turn with low activity, medium activity and high activity) of common inorganic soils $(<425 \mu \mathrm{m})$ is based on the amount and type of platey clay minerals and the two effects are incorporated into the Atterberg limit values of the tested soil.

Correlations to obtain a reliable value of the residual friction angle from the index properties values of cohesive soils appear untenable. Nevertheless, the location of Atterberg limits data on the (adapted) activity chart to predict drained residual strength behaviour of inorganic soils containing platey clay minerals proves more suitable than the existing correlations. The activity chart used for this purpose should not replace laboratory determination of residual shear strength, but it can be applied as follows:

a) to infer the residual shear behaviour of the soils $(<425$ $\mu \mathrm{m})$ and the expected range of residual friction angle values;

b) to select samples for laboratory residual strength tests;

c) to compare both the residual friction angle values (the experimental value and that which is inferred from the activity chart). If the difference is noticeable, we should try to understand the causes of the discrepancy.

Considering the very different behavioural characteristics of the soil constituents (conventionally attributed to fractions less than and greater than $2 \mu \mathrm{m}$ ), the distinction between coarse-grained soils and fine-grained soils based on their percentage of clay $(<2 \mu \mathrm{m})$ (and the Activity chart proposed), might be very useful in classifying and predicting soils' engineering behaviour.

\section{ACKNOWLEDGEMENTS}

The author is grateful to Professor Renato Lancellotta for his critical examination of this paper.

\section{REFERENCES}

1) ASTM (1990): Standard test method for particle-size analysis of soils, Test designation D 422, Am. Soc. for Testing and Materials, 04.08, West Conshohocken, PA.

2) ASTM (1993): Standard classification of soils for engineering purposes, Test Designation D 2487, Am. Soc. for Testing and Materials, 04.08, West Conshohoken, PA.

3) ASTM (1995): Standard test method for liquid limit, plastic limit and plasticity index of soils. Test designation D 4318, Am. Soc. for Testing and Materials, 04.08, West Conshohocken, PA.

4) BSI (1990): British Standard Methods of test for soils for engineering purposes, BS 1377, British Standards Institution, Milton Keynes.

5) Casagrande, A. (1932): Research on the Atterberg limits of soils, Public Roads, 13, 121-136.

6) Casagrande, A. (1948): Classification and identification of soils, Trans. ASCE, 113, 901-991.

7) Casagrande, A. (1958): Notes on the design of the liquid limit device, Géotechnique, 8, 84-91.

8) Collotta, T., Cantoni, R., Pavesi, U., Ruberl, E. and Moretti, P. C. (1989): A correlation between residual friction angle, gradation and the index properties of cohesive soils, Géotechnique, 39(2), 343-346.

9) Dewoolkar, M. M. and Huzjak, R. J. (2005): Drained residual shear strength of some claystones from Front Range, Colorado, $J$. Geotech. Geoenv. Eng., ASCE, 131(12), 1543-1551.

10) Di Maio, C. and Fenelli, G. B. (1994): Residual strength of kaolin and bentonite: the influence of their constituent pore fluid, Géotechnique, 44(4), 217-226.

11) Kanji, M. A. (1974): The relationship between drained friction angles and Atterberg limits of natural soils, Géotechnique, 24(4), 671-674.

12) Kenney, T. C. (1967): The influence of mineral composition on the residual strength of natural soils, Proc. Geotech. Conf., Oslo, 1, $123-129$.

13) Kenney, T. C. (1977): Residual strength of mineral mixtures, Proc. 9th ICSMFE, 1, 155-160.

14) Lupini, J. F., Skinner, A. E. and Vaughan, P. R. (1981): The drained residual strength of cohesive soils, Géotechnique, 31(2), 181-213.

15) Mesri, G. and Cepeda-Diaz, A. F. (1986): Residual shear strength of clays and shales, Géotechnique, 36(2), 269-274.

16) Mitchell, J. K. (1993): Fundamentals of soil behaviour, 2nd ed. John Wiley and Sons, New York, $437 \mathrm{p}$.

17) Polidori, E. (2003): Proposal for a new plasticity chart, Géotechnique, 53(4), 397-406.

18) Polidori, E. (2007): Relationship between the Atterberg limits and clay content, Soils and Foundations, 47(5), 887-896.

19) Rao, S. M. (1996): Correlation between plasticity angle and engineering properties of volcanic ash soils, Soils and Foundations, 36(2), 123-127.

20) Seed, H. B., Woodward, R. J. and Lundgren, R. (1964): Clay mineralogical aspects of the Atterberg limits, J. Soil Mech. Found. Div., ASCE, 90(SM4), 107-131.

21) Seycek, J. (1978): Residual shear strength of soils, Bull. Int. As. Eng. Geologists, 17, 73-75.

22) Skempton, A. W. (1953): The colloidal activity of clays, Proc. $3 r d$ ICSMFE, Zurich, 1, 57-61.

23) Skempton, A. W. (1964): Long-term stability of clay slopes, Géotechnique, 14(2), 77-102.

24) Skempton, A. W. (1985): Residual strength of clays in landslides, folded strata and the laboratory, Géotechnique, 35(1), 3-18.

25) So, E. K. (1998): Statistical correlation between allophone content and index properties for volcanic cohesive soil, Soils and Founda- 
tions, 38(4), 85-93.

26) Sridharan, A., Rao, S. M. and Murthy, N. S. (1986): Compressibility behaviour of homoionized bentonites, Géotechnique, 36(4), 551-564.

27) Sridharan, A., Rao, S. M. and Murthy, N. S. (1988): Liquid limit of kaolinitic soils, Géotechnique, 38(2), 191-198.

28) Stark, T. D. and Eid, H. T. (1994): Drained residual strength of cohesive soils, J. Geotech. Eng., ASCE, 120(5), 856-871.

29) Vaughan, P. R., Hight, D. W., Sodha, V. G. and Walbancke, H. J. (1978): Factors controlling the stability of clay fills in Britain, Clay fills (ICE), London, 205-217.

30) Voight, B. (1973): Correlation between Atterberg plasticity limits and residual shear strength of natural soils, Géotechnique, 23(2), 265-267.

31) Wesley, L. D. (1973): Some basic engineering properties of halloysite and allophane clays in Java, Indonesia, Géotechnique, 23(4), 471-494.

32) Wesley, L. D. (1977): Shear strength properties of halloysite and allophane clays in Java, Indonesia, Géotechnique, 27(2), 125-136.

33) Wesley, L. D. (2003): Residual strength of clays and correlations using Atterberg limits, Géotechnique, 53(7), 669-672.

34) Whyte, I. L. (1982): Soil plasticity and strength-a new approach using extrusion, Ground Eng., 15(1), 16-24. 